\title{
TRANSIÇÃO AGROECOLÓGICA NO SEMIÁRIDO BRASILEIRO: O EXPERIMENTO DO RIACHO DO MEIO, CEARÁ
}

\section{Eufrasina Campelo Borges Mendonça Barbosa ${ }^{1}$}

1. Mestra em Gestão Logística e Pesquisa Operacional - Universidade Federal do Ceará/GESLOG, Bacharel em Ciências Econômicas - Universidade Federal do Ceará/FEAAC (eufrasinabarbosa@hotmail.com) - Brasil.

Recebido em: 02/10/2017 - Aprovado em: 21/11/2017 - Publicado em: 05/12/2017 DOI: 10.18677/EnciBio_2017B108

A Comunidade do Riacho do Meio, situada no semiárido brasileiro, adotou práticas da agricultura convencional por muitos anos. Em decorrência do enfraquecimento do solo, em 1983 ocorreu a infestação do inseto "bicudo". Para superar essa situação, os agricultores dessa Comunidade procuraram apoio técnico do Escritório de Pesquisa, Planejamento e Assessoria em Desenvolvimento Rural (ESPLAR) em 2004. A motivação básica era retomar o cultivo do algodão, em novas bases. Iniciase o processo de transição agroecológica com a estruturação do Consórcio centrado no algodão Mocó. Além desta variedade, o consórcio compreende milho, feijão e gergelim, dentre outras culturas. Esta experiência tornou a Comunidade um caso de sucesso. Atualmente, estes agricultores/as compartilham seus conhecimentos com outras comunidades regionais e até internacionais. O cultivo principal continua sendo o algodão, sendo importante frisar que esta matéria-prima, produzida no Ceará, juntamente à seringa extraída na Amazônia, faz parte de uma cadeia de fabricação de tênis sediada no Rio Grande do Sul. Os modelos são comercializados em loja virtual e lojas físicas localizadas em importantes centros consumidores do Brasil, da Europa e dos USA. Os produtores de algodão e borracha participam de uma rede de comércio justo. Outro cultivo que se destaca é o gergelim que serve de matéria-prima para a atividade de extração do óleo realizada por um grupo de jovens que reside na Comunidade. A expectativa é que a adoção de práticas agroecológicas pelas famílias do Riacho do Meio se amplie e contribua para 0 aumento da biodiversidade da região e a redução de riscos sociais.

PALAVRAS-CHAVE: Agroecologia. Algodão Mocó. Consórcio.

\section{AGROECOLOGICAL TRANSITION IN THE BRAZILIAN SEMI-ARID: THE EXPERIENCE OF RIACHO DO MEIO, CEARÁ}

\begin{abstract}
The community of Riacho do Meio, located in the Brazilian semi-arid, adapted for many years conventional agriculture practices. The weakening of this soil was an advantage for the predatory action of "bicudo" in 1983. To overcome this situation, farmers from that Community requested technical support from "Escritório de Pesquisa, Planejamento e Assessoria em Desenvolvimento Rural (ESPLAR)" in
\end{abstract}


2004. The basic motivation was to resume cultivation of cotton on new bases. The process of agroecological transition begins with the structuring of an Intercropping Systems focused on Mocó cotton. Further to this variety, the system includes corn, beans and sesame, among other crops. This experience turns this Community into a success case. They currently share their knowledge among other regional and even international communities. The main crop continues to be cotton and it is important to emphasize that this input, produced in Ceará, along with the syringe extracted from Amazonia are part of a sneakers production chain located in Rio Grande do Sul. These models are sold through virtual and physical stores located in important consumer centers in Brazil, Europe and the USA. Cotton and rubber producers participate in a fair-trade network. Another crop that stands out is the sesame that serves as raw material for oil extraction, an activity performed by a group of young people residing in the Community. The main goal is that the adoption of agroecological practices by the families from Riacho do Meio expands and contributes to the increase of biodiversity and the reduction of social risks.

KEYWORDS: Agroecology. Mocó Cotton. Intercropping Systems.

\section{INTRODUÇÃO}

$\mathrm{Na}$ segunda metade do século $\mathrm{XX}$, as políticas desenvolvimentistas de JK estimularam a implantação da chamada "revolução verde" no Brasil. Autodenominada "modernização" agrícola, ela não foi nem "revolução" e, nem muito menos, "verde" (MACHADO; MACHADO FILHO, 2014). A expressão se refere a um pacote tecnológico composto por insumos químicos, variedades geneticamente modificadas e máquinas e equipamentos agrícolas (GARCIA, 2014). Essas inovações ao mesmo tempo em que aceleram a produção, contribuem para o esgotamento da fertilidade do solo. Em outras palavras, a degradação da estrutura física do solo, segundo Romeiro (2014), provoca uma contradição permanente: "quanto mais o solo se degrada, menos pode-se contar com os serviços ecossistêmicos para que sejam obtidas as condições necessárias para o cultivo, as quais têm de ser obtidas por meio de intervenções químico-mecânicas, elas próprias degradantes". Do ponto de vista ambiental, a expressão "modernização" encerra uma grave contradição, pois é antagônica à ideia de conservação. Do ponto de vista social, contribui para desestruturar o modo de vida das famílias, estimulando a formação de latifúndios e a extensividade do cultivo.

Segundo Froncheti e Zamberlam (2012), o avanço da lógica capitalista de produção no meio rural brasileiro ocorreu no período em que se instaurou o regime militar no País. O principal instrumento governamental para implantar a modernização engendrada pela "revolução verde" foi a disseminação do crédito subsidiado. Especialmente nas décadas de 1970 e 1980, o regime militar alocou grandes somas de recursos financeiros, a juros baixos, para favorecer os grandes proprietários de terras, possibilitando elevados investimentos em máquinas e insumos (sementes híbridas, fertilizantes químicos, inseticidas etc.). A implantação desse pacote tecnológico contou com profissionais treinados para implementar este sistema no campo. Com essas características, o pacote tecnológico provoca impactos ambientais importantes, em termos de erosão do solo, contaminação das águas superficiais e subterrâneas e redução da biodiversidade (ALENCAR et al., 2013). No aspecto social e econômico, desestrutura as atividades tradicionais e estimula o êxodo rural.

Em contraposição, a agroecologia prioriza a biodiversidade, em que sistemas agrícolas complexos interagem de modo a potencializar os serviços ambientais. ENCICLOPÉDIA BIOSFERA, Centro Científico Conhecer - Goiânia, v.14 n.26; p. 1295 2017 
Para Altieri (2012), a conservação é o princípio central da agroecologia. Segundo o autor, é por meio da compreensão mais profunda da ecologia dos agroecossistemas que surgirão novas percepções e alternativas de manejo em maior sintonia com os objetivos de uma agricultura verdadeiramente sustentável. Toledo e Barrera-Bassols (2015) sugerem que ciência agroecológica retoma os saberes tradicionais, pois resgata a memória biocultural das comunidades. O produto da agroecologia não atende às imposições do mercado, ao contrário, satisfaz subsistência dos agricultores, cujo modo de vida caminha (pegada ecológica) em coevolução com a Natureza.

Ainda que agroecologia expresse técnicas de cultivos menos agressivas à Natureza e às pessoas, é fundamental destacar outros aspectos que compõem a diversidade de sentidos deste termo. A ciência agroecológica prioriza a biodiversidade em que sistemas agrícolas complexos interagem de modo a potencializar os serviços ambientais (ALTIERI, 2012). Além disso, inclui as dimensões políticas e culturais pertinentes à história de luta dos camponeses pela terra. Essas diferentes perspectivas se reforçam na construção de um corpo de conhecimentos capaz de "orientar a conversão dos sistemas convencionais de produção (monocultivos dependentes de insumos químicos) a sistemas diversificados e autossuficientes" (ALTIERI; NICHOLLS, 2007). Esses autores referem-se à "agroecologia como um conjunto de formas coletivas de manejo dos recursos naturais", ou ainda, em seu sentido mais amplo, como um novo "modo de vida".

$\mathrm{Na}$ Comunidade do Riacho do Meio se adotava práticas da agricultura convencional no início de sua estruturação em 1978. O monocultivo do algodão Mocó arbóreo, semiperene e resistente à seca, representava a principal fonte de renda por ser mais bem adaptado ao semiárido. O preparo do solo era precedido de queimada, destoca e uso de inseticidas durante a fase de crescimento das plantas. Em 1983, certamente pelo enfraquecimento do solo decorrente dessas práticas, a ação predatória do "bicudo"1, ocasionou uma redução significativa da área cultivada com essa variedade de algodão (BELTRÃO, 2009). Segundo Beltrão (2009) essa infestação contribuiu para a busca por técnicas de cultivo adequadas à conservação da agrobiodiversidade, respeitando os interesses e as necessidades da população envolvida e sua condição socioeconômica e cultural.

A expectativa com este relato de caso é difundir a experiência do Riacho do Meio, localizada no município de Choró, semiárido cearense, a qual tornou-se referência, recebendo vários grupos de agricultores, pesquisadores e técnicos do Ceará e do Nordeste, e até mesmo do exterior, interessados em conhecer essa realidade. Assim, relatar este caso ganha relevância como registro de um exemplo de transição bem-sucedido que contribui para o aumento da agrobiodiversidade da região, redução de riscos sociais relacionados à emigração de jovens, autonomia política, soberania alimentar e hídrica.

\section{RELATO DO CASO}

A Comunidade do Riacho do Meio está situada no sertão central do Ceará e ocupa uma área de 1.480ha. Em 1978, o dono da terra decidiu vendê-la aos 8

\footnotetext{
${ }^{1} \mathrm{O}$ bicudo é um inseto prejudicial ao plantio do algodão pelos danos que causa e pela dificuldade de seu controle devido a sua rápida infestação. Descrito por C. H. Boheman em 1843 como Anthonomus grandis, o bicudo teve a primeira constatação no Brasil em fevereiro de 1983, no município de Campinas, oriundo dos Estados Unidos. Nesse mesmo ano, esse inseto foi se alastrando da região de São Paulo para as demais áreas brasileiras produtoras de algodão, inclusive o Nordeste (AZAMBUJA; DEGRANDE, 2014).
} 
moradores mais antigos da fazenda, cada parcela variando entre 175 e 216 hectares. Nessa época as famílias dos novos proprietários se dedicavam ao plantio de ciclo curto (milho, feijão, fava), em moldes convencionais, tendo o algodão mocó arbóreo como principal fonte de renda.

Entre 1975 e 1982 a área total cultivada, no Brasil, com algodão Mocó arbóreo, da espécie Gossypium arboreum L., oscilava entre 2.000 .000 a 2.500 .000 ha (IBGE, 1978; 1982; 1983). A partir de 1983, o cultivo dessa variedade sofreu a infestação do "bicudo" (RAMALHO et al., 2000) o que reduziu significativamente a safra para quase a metade nos anos 1983 e 1984 (IBGE, 1986). Essa infestação pode ter sido reforçada pela predominância do monocultivo do algodão, associado às práticas agrícolas convencionais que provocaram alterações ecossistêmicas favoráveis ao besouro, tais como exaustão do solo e ineficácia dos inseticidas (ROMEIRO, 2014). Com avanço do inseto em direção ao nordeste brasileiro, muitos produtores abandonaram essa atividade agrícola, ocasionando o deslocamento do cultivo desta região em direção ao centro-oeste (BELTRÃO, 2009).

No Ceará, a ONG ESPLAR inicia, no período de 1991 a 1995, a pesquisa "Manejo ecológico do algodoeiro Mocó visando a convivência com o bicudo" (SOUSA et al., 2005). Essa pesquisa envolveu agricultores de sete municípios, totalizando 33 experimentos. Agricultores familiares de diferentes municípios, inclusive Choró, contribuíram para esse estudo. As áreas experimentais de produção consorciada foram negociadas pela Associação de Desenvolvimento Educacional e Cultural de Tauá - ADEC. A pesquisa participativa estimula à autossuficiência das comunidades sertanejas e contribui para o desenvolvimento socioeconômico dessa região. Como resultado importante dos experimentos, 130 agricultores tiveram seus solos recuperados, embora somente parte deles tenham assimilado as técnicas de plantio em nível e o uso da leucena no consórcio com algodão.

No caso do Riacho do Meio, é possível identificar práticas de cultivo caracterizadamente agroecológicas. Na Comunidade, o manejo agroecológico inclui o uso de substrato orgânico, biofertilizantes, técnicas de rotação e associações de cultivos, sistema consorciado de algodão, batata doce, feijão, milho e gergelim. Nesse sistema de cultivo, em que prevalece a agrobiodiversidade, as plantas de mesma espécie são intercaladas por outras diferentes, isto contribui para confundir o inseto em seu processo de aproximação. A agrobiodiversidade, apenas, não elimina a possibilidade de infestações. Quando isso ocorre, os agricultores do Riacho do Meio utilizam uma mistura composta pelo extrato da folha de angico e pela semente do Nim, junto com urina da vaca prenhe. Como um resultado prático diminui a população de insetos.

Com relação à segurança hídrica, as famílias coletam água da chuva em cisternas para consumo humano, animal e irrigação (COSTA, 2013). As cisternas têm formato circular e resultam da montagem de placas de cimento sobrepostas. Aquelas que armazenam água para beber e cozer alimentos têm capacidade de 16 mil litros e são abastecidas pela chuva que cai nos telhados das residências. Outro tipo, conhecido por "cisterna calçadão", que armazena a água proveniente de uma superfície plana retangular com declive, acumula 52 mil litros, tem por finalidade a irrigação das hortaliças e o consumo doméstico e de animais.

A segurança hídrica é garantida pelas cisternas e a autonomia diante da política estatal de distribuição de sementes, pela "casa de sementes". Nela se encontram adequadamente armazenadas as sementes que serão utilizadas no próximo cultivo. Com essa tecnologia social os agricultores e as agricultoras 
garantem a preservação das chamadas sementes crioulas, estocando as variedades mais adaptadas ao local.

Não obstante, o cultivo do algodoeiro em bases agroecológicas continua sendo difundido junto a agricultores de outros municípios além do Choró. A proposta inovadora foi a estruturação do Consórcio Agroecológico centrado no algodão Mocó arbóreo, com certificação orgânica participativa (CARDOSO, 2017). De acordo com Balestro e Sauer (2013), o sistema agroecológico envolve combinações entre espécies anuais e perenes. As culturas consorciadas são dispostas de maneira simultânea ou sequencial, o mesmo ocorrendo com as colheitas. Esta técnica de cultivo e tecnologia social despontam como uma solução viável para manter os agricultores em suas atividades e oferece alternativa de cultivo para o semiárido nordestino (VENTURA et al., 2012).

A parceria entre o ESPLAR e as associações de agricultores abriu perspectivas em termos do comércio internacional de algodão orgânico. Nesse circuito, a empresa francesa Vert Shoes participa fabricando tênis com algodão cearense. A pluma é vendida à empresa francesa, que adota o sistema de comércio justo. O algodão do Ceará e a borracha da Amazônia compõem as matérias-primas da produção de tênis comercializados em loja virtual e lojas físicas localizadas em importantes centros consumidores do Brasil, da Europa e dos USA. Essa rede de fair trade possibilita o pagamento pelas matérias-primas de 30-65\% acima dos preços de mercado - índice NYBOT (New York Board of Trade). A produção de algodão ainda é insuficiente para atender a demanda dessa empresa. Por isso, é necessário ampliar o número de famílias participantes do consórcio.

Uma opção para ampliar a renda dos agricultores e agricultoras que cultivam o algodão consorciado ao gergelim, até 2013, era a venda dessa variedade in natura. Em outubro de 2014, incentivados pela Associação Comunitária dos Agricultores Familiares do Riacho do Meio (ACAF), um grupo de jovens da Comunidade se reuniu para iniciar a extração de óleo do gergelim e a produção de outros derivados desta oleaginosa, como paçoca e espécie: doce composto por gergelim, rapadura e gengibre. Cria-se, então, o grupo Jovens Sementes do Sertão (GJSS). A comercialização desses produtos ocorre junto às famílias que residem na Comunidade, nos municípios da região e de outros estados do Nordeste. Em síntese, a adoção da agroecologia na Comunidade do Riacho do Meio envolve múltiplas dimensões necessárias a um modo de vida adequado às condições biofísicas que são próprias do semiárido. Não se trata apenas de técnicas de cultivo, mas de coevolução entre atividades produtivas e a Natureza.

\section{DISCUSSÃO}

Diferentemente do modelo da agricultura convencional em que se utilizam insumos químicos (industrialmente produzidos), variedades geneticamente modificadas e mecanização, a Comunidade aqui analisada prioriza o uso de insumos internos, diversificação de culturas, trabalho familiar e mutirões. Tais mudanças estão centradas nos princípios da ciência agroecológica que, além de estar associada à ecologia e à proteção do ambiente, também se insere na construção de uma sociedade de produtores cooperativos, livremente associados, cujas intervenções são participativas e democráticas. Assim, a agroecologia propicia aos agricultores familiares consciência política e autonomia econômica. Tal autonomia na gestão familiar ou coletiva dos recursos naturais configura um componente essencial para a continuidade e ampliação das práticas agroecológicas. 
A efetivação dessas práticas decorre de um processo de transição que conduz a ecologização dos sistemas produtivos agrícolas e das atividades rurais. Segundo Machado e Machado Filho (2014, p. 38) é preciso "abandonar o modelo convencional" e, em seu lugar, estudar e incorporar os saberes bioculturais que, ao mesmo tempo, preservam a Natureza e resgatam as práticas tradicionais de cultivo, propiciando aos produtores bem-estar socioeconômico e ambiental.

A conversão de sistemas produtivos de agricultura convencional para sistemas de base agroecológica é uma construção ecosocial que emerge das interações que se estabelecem entre atores, recursos e atividades de maneira localizada. Schmitt (2013) afirma que a formação dos agricultores familiares e campesinos no sentido da apropriação cultural e da nova construção social são fundamentais para conduzir a transição agroecológica.

\section{CONCLUSÃO}

Com essa breve sistematização da experiência da Comunidade do Riacho do Meio é possível perceber as possibilidades que podem ser vislumbradas no sentido da disseminação de práticas agroecológicas nas condições edafoclimáticas do semiárido do Ceará. A ampliação das atividades produtivas previstas nos projetos em andamento reafirma o processo de consolidação de um percurso que se iniciou em 2004, quando da decisão de extirpar práticas que exauriam o solo e a biodiversidade do território. Nesse sentido, o ESPLAR permanece desenvolvendo ações para ampliar a adesão dos agricultores/as familiares ao consórcio agroecológico, não apenas no Choró, mas também em outros municípios do sertão cearense.

Diversas reuniões de sensibilização têm sido realizadas em territórios onde essa prática ainda não adquiriu expressividade. São momentos para demonstrar aos potenciais participantes do consórcio a importância da agroecologia para a saúde humana e ambiental e para a coesão social. Aqueles e aquelas que se interessam em replicar a experiência do Riacho do Meio, a partir do cultivo agroecológico centrado do algodão, são informados quanto à garantia de compra de toda a produção pela Vert Shoes. A produção atual de algodão agroecológico no Ceará é insuficiente para atender a demanda dessa empresa. Isso reforça a necessidade de ampliar o número de famílias participantes do consórcio.

Um instrumento importante é o fortalecimento da ACAF, Associação Comunitária dos Agricultores Familiares do Riacho do Meio, que foi fundada em 1995, com a finalidade de encaminhar demandas coletivas e individuais de seus associados ao poder público, tais como projetos voltados para a produção e comercialização de produtos agrícolas e não agrícolas e melhoria das condições de vida das famílias residentes, contribuindo, para obtenção de importantes infraestruturas, como energia elétrica. Esse nível de organização fortifica a coesão interna da Comunidade dando-Ihes condições para a autogestão de seus projetos, garantindo autonomia política aos agricultores e agricultoras.

Outro projeto importante é o da ampliação da unidade de processamento de derivados do gergelim, seguindo rigorosos padrões sanitários. A comunidade, através de um edital da Fundação Banco do Brasil e com os investimentos do Instituto C\&A, conseguiu construir um galpão exclusivo para 0 trabalho com 0 gergelim, além de máquinas mais adequadas. As novas instalações e equipamentos possibilitaram ganhos de eficiência no processo de produção e melhores condições para a formação dos jovens em novas práticas culinárias, como a fabricação de paçoca e espécie (doce composto por gergelim, rapadura e gengibre). $\mathrm{O}$ aumento 
da produção daí decorrente proporcionará uma renda adicional às famílias. Por fim, a próxima etapa é desenvolver canais permanentes de comercialização, incluindo-se vendas em feiras agroecológicas em municípios da região e de Fortaleza.

\section{REFERÊNCIAS}

ALENCAR, G. V. de; MENDONÇA, E. de S.; OLIVEIRA, T. S. de; JUCKSCH, I.; CECON, P. R. Percepção ambiental e uso do solo por agricultores de sistemas orgânicos e convencionais na Chapada da Ibiapaba, Ceará. Revista de Economia e Sociologia Rural, Brasília, v. 51, núm. 2, p. 217-236, 2013.

ALTIERI, M. Agroecologia: Bases científicas para a agricultura sustentável. Guaíba: Agropecuária, 2012.

ALTIERI, M.; NICHOLLS, C. I. Conversión agroecológica de sistemas convencionales de producción: teoría, estrategias y evaluación. Revista Ecossistemas, v. 16, n. 1, 2007.

AZAMBUJA, R.; DEGRANDE, P. E. Trinta anos do bicudo-do-algodoeiro no Brasil. Arquivos do Instituto Biológico, São Paulo, v.81, núm. 4, p. 377-410, dez/2014. Disponível em <http://dx.doi.org/10.1590/1808-1657000012013>. Epub 28 nov. 2014. Acesso em: 26 out. 2017.

BALESTRO, M. V.; SAUER, S. (orgs.). Agroecologia e os desafios da transição agroecológica. 2ª Edição, São Paulo: Expressão Popular, 2013.

BELTRÃO, N.E. de M. Algodão agroecológico: opção de agronegócio para o semiárido do Brasil. Documentos no 222. Campina Grande: Embrapa Algodão, 2009.

CARDOSO, N. F. S. Algodão agroecológico no semiárido brasileiro: da produção à comercialização. Viçosa, MG, 2017.

COSTA, A. B. (org.). Tecnologia Social e Políticas Públicas. São Paulo: Instituto Pólis. Brasília: Fundação Banco do Brasil, 2013.

FRONCHETI, A.; ZAMBERLAM, J. Agroecologia - Caminho de Preservação do Agricultor e do Meio Ambiente. Petrópolis, Rio de Janeiro: Vozes, 2012.

GARCIA, J. R. Trabalho rural: tendências em face das transformações em curso. In: BUAINAIN, A. M.; ALVES, E.; SILVEIRA, J. M. F. J.; NAVARRO, Z. (orgs.). 0 mundo rural no Brasil do século 21: A formação de um novo padrão agrário e agrícola. $1^{a \underline{a}}$ ed. Brasília/DF: Embrapa Informação Tecnológica, v. 1, p. 559-589, 2014.

IBGE. Instituto Brasileiro de Geografia e Estatística. Anuário estatístico do Brasil. Rio de Janeiro: Secretaria de Planejamento da Presidência da República, p. 760, 1986.

Anuário estatístico do Brasil. Rio de Janeiro: Secretaria de Planejamento da Presidência da República, p. 987, 1983. 
Anuário estatístico do Brasil. Rio de Janeiro: Secretaria de Planejamento da Presidência da República, p. 901, 1982.

Anuário estatístico do Brasil. Rio de Janeiro: Secretaria de Planejamento da Presidência da República, p. 893, 1978.

MACHADO, L. C. P.; MACHADO FILHO, L. C. P. Dialética da agroecologia. 1 Edição. São Paulo: Expressão Popular, 2014.

RAMALHO, F. de S.; MEDEIROS, R. S.; LEMOS, W. P. Bicudo-do- algodoeiro, Anthonomus grandis (Coleoptera: Curculionidae). In: VILELA, E. F.; ZUCCHI, R. A.; CANTOR, F. Pragas introduzidas no Brasil. São Paulo: Holos, p. 113-119, 2000.

ROMEIRO, A. R. O agronegócio será ecológico. In: BUAINAIN, A. M.; ALVES, E.; SILVEIRA, J. M. F. J.; NAVARRO, Z. (orgs.). O mundo rural no Brasil do século 21: A formação de um novo padrão agrário e agrícola. 1aㅡ ed. Brasília/DF: Embrapa Informação Tecnológica, v. 1, p.509-529, 2014.

SCHMITT, C. J. Transição agroecológica e desenvolvimento rural: um olhar a partir da experiência brasileira. In: BALESTRO, M. V.; SAUER, S. (orgs.). Agroecologia e os desafios da transição agroecológica. 2a Edição, São Paulo: Expressão Popular, p. 173-198, 2013.

SOUSA, I. S. de; OLIVEIRA, T. S. de; LIMA, P. J. B. F.; LEMOS, J. de J. S. Manejo agroecológico do algodoeiro arbóreo: alternativa para a agricultura familiar no semiárido cearense. Revista Ceres, v. 52, núm. 303, 2005, p. 787-809 Universidade Federal de Viçosa: Viçosa, Brasil.

TOLEDO, V. M. BARRERA-BASSOLS, N. A Memória biocultural: a importância ecológica das sabedorias tradicionais. São Paulo: Expressão Popular, 2015.

VENTURA, A. C.; GARCÍA, L. F.; ANDRADE, J. C. S. Tecnologias sociais: as organizações não governamentais no enfrentamento das mudanças climáticas e na promoção de desenvolvimento humano. Cadernos EBAPE/BR, 2012. 